\title{
Richard Scheller and Thomas Südhof receive the 2013 Albert Lasker Basic Medical Research Award
}

$\mathrm{N}$ eural communication underlies all brain activity. It governs our thoughts, feelings, sensations, and actions. But knowing the importance of neural communication does not answer a central question of neuroscience: how do individual neurons communicate? We know that communication between two neurons occurs at specialized cell junctions called synapses, at which two communicating neurons are separated by the synaptic cleft. The presynaptic neuron releases chemicals, known as neurotransmitters, into the synaptic cleft in which neurotransmitters bind to receptors on the surface of the postsynaptic neuron. Neurotransmitter release occurs in response to an action potential within the sending neuron that induces depolarization of the nerve terminal and causes an influx of calcium. Calcium influx triggers the release of neurotransmitters through a specialized form of exocytosis in which neurotransmitterfilled vesicles fuse with the plasma membrane of the presynaptic nerve terminal in a region known as the active zone, spilling neurotransmitter into the synaptic cleft.

By the 1950s, it was clear that brain function depended on chemical neurotransmission; however, the molecular activities that governed neurotransmitter release were virtually unknown until the early 1990s. This year, the Lasker Foundation honors Richard Scheller (Genentech) and Thomas Südhof (Stanford University School of Medicine) for their "discoveries concerning the molecular machinery and regulatory mechanisms that underlie the rapid release of neurotransmitters." Over the course of two decades, Scheller and Südhof identified and characterized a set of proteins that mediate the fusion of neurotransmitter-filled synaptic vesicles with the plasma membranes of presynaptic nerve terminals. These proteins participate in the formation and regulation of a membrane-bridging complex, known as the soluble NSF attachment protein (SNAP) receptor (SNARE) complex. It is now known that this mechanism is used to mediate various forms of exocytosis throughout the body.

\section{Setting the stage}

The establishment of the central tenets of neural communication required nearly a century of research. The notion of synapses, at which a neuron sends a signal to a muscle cell, was first raised by Emil du Bois Reymond in the 1860s (1). In the 1880 s, the concept of discrete, individual cells, or neurons, comprising the nervous system had been established by the anatomists Santiago Ramón y Cajal and Heinrich Wilhelm Gottfried von WaldeyerHartz, among others (Figure 1 and refs. $2,3)$. Within 50 years, Otto Loewi and Sir Henry Hallet Dale demonstrated that acetylcholine functioned as a mediator of neural communication, establishing chemical neurotransmission. From the 1950 s to the 1970s, electrophysiological studies and electron microscopy revealed that neurotransmitters are released from presynaptic nerve terminals in discrete quanta (Figure 1 and refs. 4-8). By the mid-1970s, work performed primarily by Bernhard Katz demonstrated that calci-
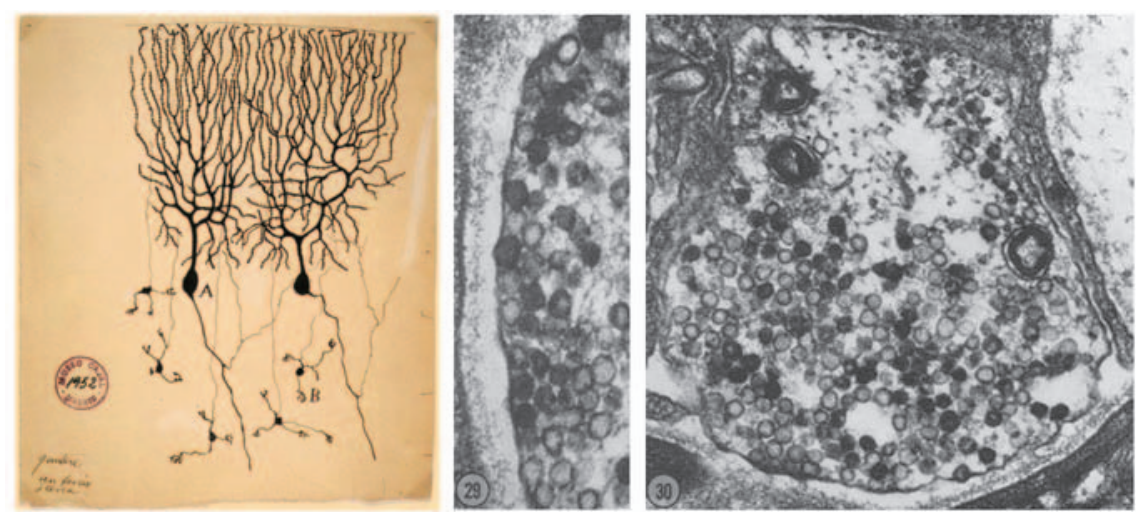

\section{Figure 1}

Starting in the late 1880s, anatomists, including Santiago Ramón y Cajal and Heinrich Wilhelm Gottfried von Waldeyer-Hartz, proposed that the nervous system is made up of individual cells, a concept known as the neuron doctrine, which is illustrated in Ramón y Cajal's 1899 drawing of Purkinje cells from the pigeon cerebellum (left; image in the public domain). By the mid-1950s, it was apparent that neurons communicated with each other via chemical synapses. Electron microscopy experiments revealed that neurotransmitters were released from membranous vesicles stored in the nerve endings, as seen in the accompanying electron micrograph (middle and right) (copyright 1973 Rockefeller University Press. Originally published in Journal of Cell Biology. 57:315-344. doi: 10.1083/jcb.57.2.315; ref. 8). It took 40 more years to elucidate the molecular mechanisms that govern neurotransmitter release. 

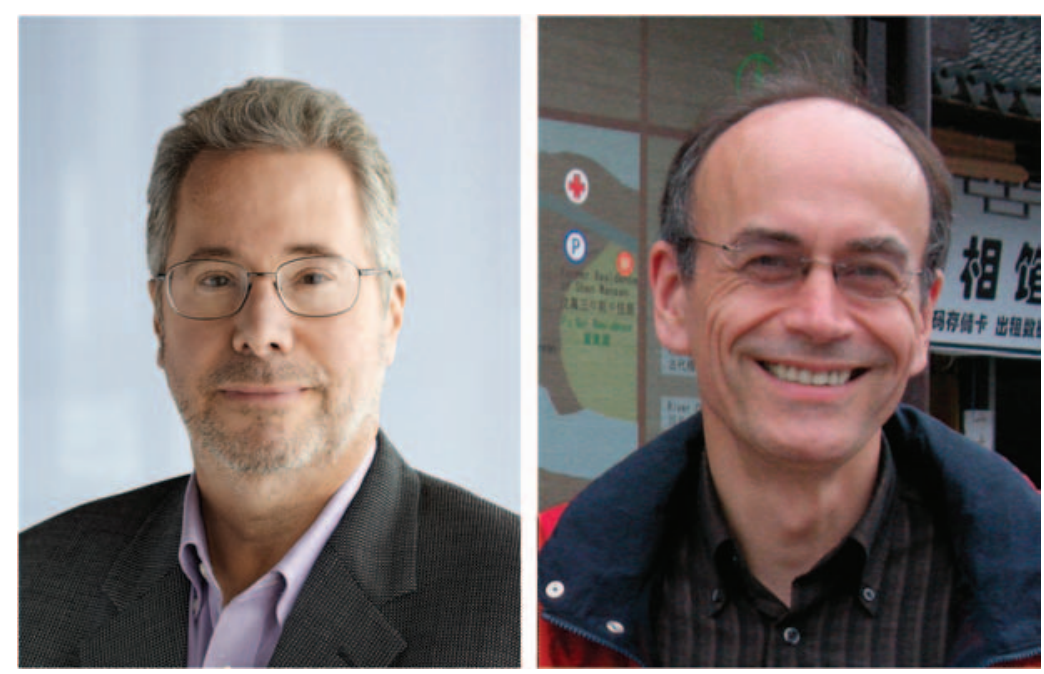

Figure 2

Richard Scheller (Genentech, left) and Thomas Südhof (Stanford University School of Medicine, right) won the 2013 Albert Lasker Basic Medical Research Award for elucidating the molecular and regulatory mechanisms that mediate neurotransmitter release.

opment of the neuromuscular junction in the electric lobe of the Torpedo californica ray. Scheller's lab developed an expression cDNA library to clone agrin, a protein that helps organize acetylcholine receptors at the presynaptic nerve terminal. McMahon's lab raised an antibody against the agrin protein, for what turned out to be a productive collaboration. These studies prompted Scheller to consider other problems in neuroscience, including the mechanism of neurotransmitter release. Scheller knew that others had raised antibodies against purified synaptic vesicles. "I thought if I could get some of that antibody, I could screen the cDNA library and find the genes encoding the proteins that are present on the synaptic vesicles and then by studying those proteins, we might be able to understand the neurotransmitter release process," said Scheller.

Thomas Südhof first studied neuroscience while completing his doctoral degree at the Max Planck Institute for Biophysical Chemistry, where his research dealt with the release of hormones from adrenal cells, a form of neurotransmitter release. In 1983, Südhof moved to the University of Texas Southwestern Medical Center (UT Southwestern) to work as a postdoctoral researcher in the lab of Michael Brown and Joseph Goldstein. During this period, he cloned the LDL receptor gene and studied its regulation by cholesterol. Südhof turned his attention back to neuroscience when he became an assistant professor at UT Southwestern in 1986, working to identify and characterize the molecules that mediated the release of neurotransmitters. "My hypothesis was extremely simple," said Südhof. "Basically, we have a structure that is clearly abundant in the brain and we don't know a single protein that creates it. In order to understand it, we have to find out what is there. The whole idea was to take it apart."

\section{Vesicle-associated membrane proteins}

The characterization of molecular mediators of synaptic membrane fusion began in 1987 when Südhof cloned the first synaptic vesicle protein, synaptophysin (13). In June 1988, Scheller and colleagues used an antibody to purified synaptic vesicles from an electric ray made by Regis Kelly (14) to screen the Torpedo cDNA expression library. They were looking for vesicleassociated proteins and identified vesicleassociated membrane protein 1 (VAMP1), which would become the first of the SNAREs, a large family of proteins that mediate vesicle fusion (see below) (15). Less than a year later, Südhof's group, in collaboration with Reinhard Jahn, identified the mammalian and Drosophila homologs of Torpedo VAMP1, termed synaptobrevin (16). In July 1989, Scheller used Torpedo VAMP1 to isolate two independent classes of VAMP cDNA clones that were differentially expressed in rat CNS (17). A follow- up paper in April 1990 showed that VAMP1 was specifically localized to nerve cells involved in somatomotor functions, while VAMP2 was more ubiquitously expressed (18). Both Scheller and Südhof suggested that VAMP1/synaptobrevin played a critical role in neurotransmission. These initial findings set off a decade-long volley of papers from the two groups, with each identifying crucial actors in neurotransmitter release.

While Scheller and Südhof were exploring the basic principles of neural communication, James Rothman began characterizing proteins that would eventually be shown to be integral to the process of neurotransmitter release. He identified several cytosolic components of the vesicle fusion machinery in nonneuronal eukaryotic cells. In 1988, his group purified N-ethylmaleimide-sensitive protein (NSF), which promoted transport vesicle fusion in the Golgi $(19,20)$. A short time later, the group found SNAPs, which are required for NSF attachment to the Golgi (21-23). Additional experiments in yeast indicated that these components of the vesicle fusion machinery were evolutionarily conserved $(24,25)$. They later demonstrated that NSF and SNAPs interacted with an unidentified integral membrane protein, forming a multisubunit protein complex, referred to as the $20 \mathrm{~S}$ complex (26). These seemingly unrelated proteins eventually played a critical role in understanding neural communication, with the development of the SNARE hypothesis (see below).

\section{The calcium trigger}

While research in the 1970s had shown that calcium was required to instigate neurotransmitter release, the molecular trigger for this event was unknown (27). A 1981 study by Louis Reichardt and colleagues at the University of California, San Francisco, identified a 65-kDa protein on the outer surface of rat synaptic vesicles (28). However, it wasn't until 1990 that Südhof's group purified the protein, cloned it, and determined that the cytoplasmic domain of p65 contained C2 regions, which exhibited sequence similarity to a region of PKC of unknown function. Südhof showed that the C2 domains bound phospholipids and proposed that p65 (later termed synaptotagmin) could mediate membrane interactions in a calcium-dependent manner (29). Within the year, Südhof identified the human and Drosopbila homologs of p65 (30) and a 


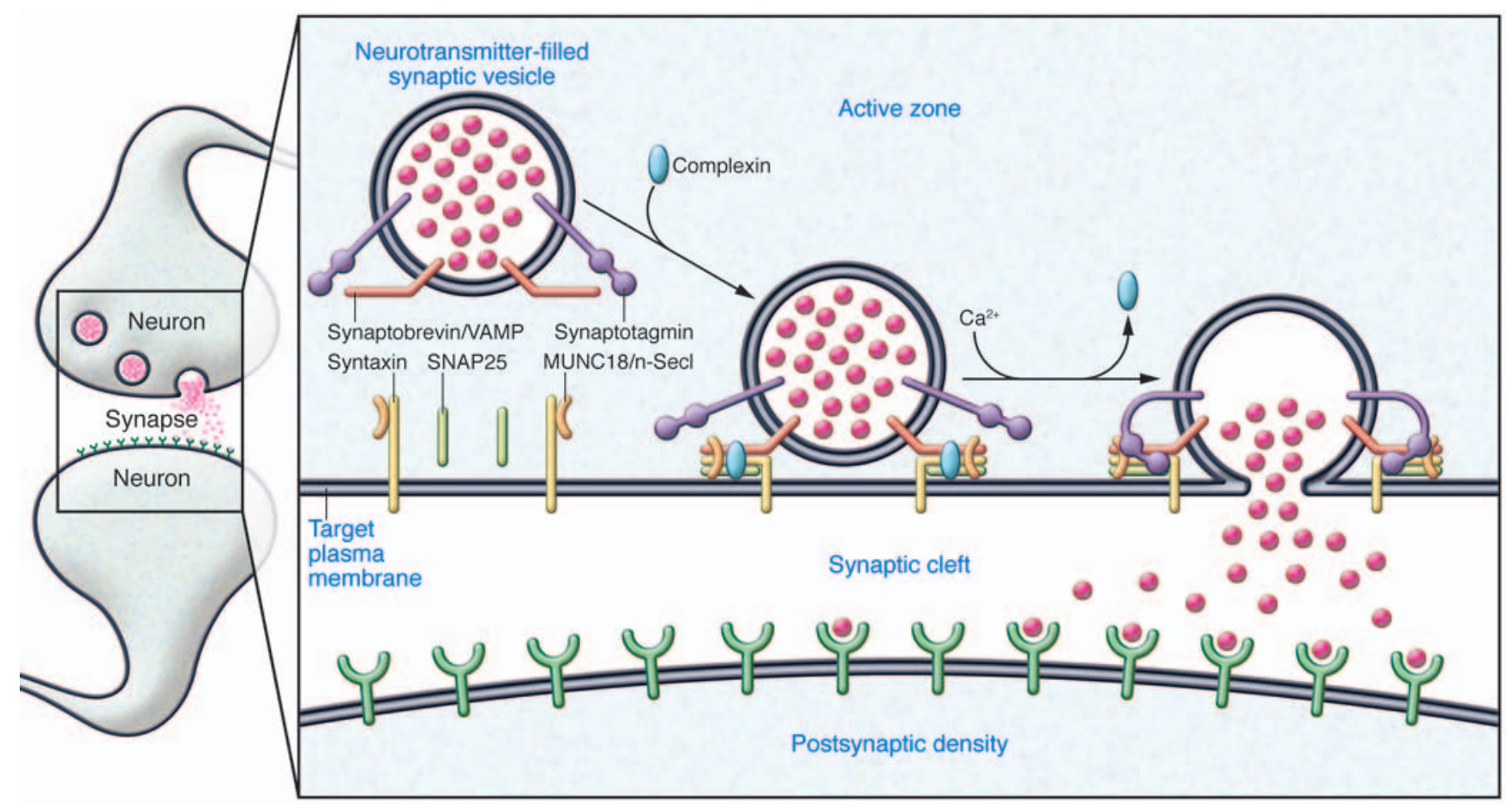

Figure 3

SNARE-mediated synaptic vesicle exocytosis. Prior to exocytosis, the synaptic vesicles are filled with neurotransmitter and translocate to the active zone, where they dock at morphologically defined sites on the target plasma membrane. The v-SNARE synaptobrevin/VAMP faces the target plasma membrane, which contains the v-SNAREs SNAP25 and syntaxin, which associates with MUNC18/n-Sec1. During the priming stage of vesicle fusion, the SNARE proteins partially zipper together and complexin clamps the SNARE complex in an activation-poised state to prevent membrane fusion. Action potential-induced calcium influx triggers calcium, phospholipid, and SNARE complex binding by synaptotagmin, which causes displacement of complexin and opening of the fusion pore. Vesicle/target membrane fusion allows neurotransmitter to enter the synaptic cleft and interact with the postsynaptic density of the partner neuron (inset).

second form of synaptotagmin that was differentially expressed in the CNS (31). Scheller's group identified three more p65-related genes in the marine ray Discopyge ommata, all of which contained regions that were highly similar to the PKC regulatory domain (32), and Südhof identified an additional four isoforms (33). Taken together, these results suggested that synaptotagmin is highly conserved and likely to function in the trafficking of synaptic vesicles (34).

Südhof's group performed many additional studies to establish synaptotagmin as a calcium sensor in vesicle exocytosis. $\mathrm{He}$ showed that the $\mathrm{C} 2$ domain constitutes an autonomously folded, calcium-regulated domain in synaptotagmin, a finding that enabled the discovery of the $\mathrm{C} 2$ domain as a general calcium-regulated domain that is present in many proteins, including PKC (35). Synaptotagmin was found to interact with several different synaptic plasma membrane proteins, including $\omega$-conotoxin-sensitive calcium channels (36), the $\alpha$-latrotoxin receptor (37), and active zone-expressed syntaxins (described below) $(38,39)$, providing evidence that it played a role in synaptic vesicle docking at the active zone. Scheller's group followed up with a study showing that injection of synaptotagmin-targeted antibodies into PC12 cells reduced regulated vesicle exocytosis (40).

Südhof speculated that as a putative calcium sensor for neurotransmitter release, synaptotagmin might not be important for fusion of synaptic vesicles as such, but could be selectively essential for calcium-triggered synchronous fast release. This prediction was confirmed in the electrophysiological analyses of synaptotagmin knockout mice performed by Südhof in 1994, which revealed that synaptotagmin is not required for vesicle exocytosis as such, but only for fast, calcium-triggered exocytosis (40). It took Südhof's laboratory nearly another decade to formally prove that calcium binding to synaptotagmin is the trigger for synchronized neurotransmitter release $(41,42)$.

\section{Targeting the plasma membrane: syntaxin, SNAP25, and MUNC18}

Despite their early success in the identification of the vesicle-associated proteins, researchers still had no clear idea how the vesicles actually fused with the presynaptic plasma membrane. In July 1992, Scheller and colleagues isolated two $35-\mathrm{kDa}$ proteins, called syntaxins, which coimmunoprecipitated with synaptotagmin from rat synaptic vesicle fractions (38). Syntaxins had previously been cloned by two different groups in another context, but Scheller's work was the first to link them to the synapse. The syntaxins were expressed abundantly in the CNS and interacted with $\mathrm{N}$-type voltage-gated calcium channels, a component of the presynaptic active zone that is required for neurotransmitter release (43). "With syntaxin, the exciting thing was, while we immunoprecipitated with a vesicle protein, the syntaxin protein was located on the plasma membrane - now we had a link between the vesicle and the plasma membrane," said Scheller. They further sug- 
gested that the combination of VAMP, syntaxin, and synaptotagmin formed a scaffold for assembly of the soluble factors $\alpha$-SNAP and NSF that Rothman had isolated. These findings were expanded in a 1993 paper suggesting that the syntaxins specify target membranes for vesicle fusion (44).

Prior to the discovery of syntaxin, Michael Wilson and colleagues at the Research Institute of Scripps Clinic had identified a protein known as SNAP25 (45). They isolated cDNA clones encoding neuronal-specific mRNA that encoded a $25-\mathrm{kD}$ a synaptosomal protein and used immunocytochemistry and protein fractionation to determine that it was located in the presynaptic terminals of hippocampal mossy fibers and the inner molecular layer of the dentate gyrus. Intriguingly, SNAP25 did not contain a hydrophobic region that would be compatible with a transmembrane region; however, the authors concluded that it was likely to play a role in synaptic function based on its localization and association with other presynaptic proteins. This role would not be fully understood until 1993 with the presentation of the SNARE hypothesis.

Südhof purified a fourth essential component of the fusion machinery, the syntaxin-binding protein MUNC18, in 1993 (46). The following year, Scheller also cloned MUNC18 from rat brain and named it $\mathrm{n}$-Sec1 for its homology to the yeast secretory protein Sec1 (47). The observation that MUNC18 is a SNAREbinding protein helped define the function of yeast Sec1 and led to the identification of the Sec1/MUNC18-like (SM) protein family. It was suggested early on that Munc18 played an essential role in the fusion machinery; however, it has only been shown in the last decade that SM proteins generally associate with SNARE complexes during fusion and partner with SNAREs in all fusion reactions $(46,48)$.

\section{Toxins reveal function}

The naturally occurring neurotoxins tetanus and botulinum inhibit neurotransmitter release and provided insight into the mechanisms of neuronal communication. In particular, tetanus toxin induces spastic paralysis by blocking neurotransmitter release in the CNS, while botulinum toxin induces flaccid paralysis by inhibiting acetylcholine release in the neuromuscular junction. In 1992, the targets of these toxins were unknown, but a study by Cesare Montecucco's group at the University of Padua demonstrated that both tetanus and botuli- num toxins block neurotransmitter release in Aplysia by cleaving VAMP1/synaptobrevin (49). A month later, Südhof and Jahn published similar findings with synaptosomes and tetanus toxin (50). Additionally, Südhof identified the VAMP2 homolog cellubrevin, a ubiquitously expressed protein that was also a tetanus toxin substrate (51). These studies represent the first direct evidence of a role for VAMPs/synaptobrevin in neurotransmitter release. "If you take the clostridial neurotoxins, the discovery that their substrates were SNAREs was probably the seminal discovery that identified SNAREs as components of fusion machinery. That was clearly a milestone in understanding fusion. It didn't answer the entire question, but it provided a crucial piece," said Südhof.

Südhof characterized synaptotagmin's function using $\alpha$-latrotoxin, which is secreted by black widow spiders and induces neurotransmitter release. He found that $\alpha$-latrotoxin binds directly to synaptotagmin and modulates its phosphorylation (37). These findings helped to confirm the role of synaptotagmin, and the importance of its phosphorylation state, in neurotransmitter release.

As noted above, botulinum neurotoxin induces flaccid paralysis by blocking acetylcholine release at the neuromuscular junction. Südhof, in collaboration with Jahn and Neimann, found that botulinum neurotoxin A mediates proteolysis of SNAP25 (52), a finding that was quickly confirmed by Michael Wilson and Cesare Montecucco (53). Shortly afterward, Jahn showed that botulinum toxin $\mathrm{C}$ cleaves and inactivates syntaxin (54), which was confirmed a little over a year later by Montecucco and Scheller (55).

\section{Putting the pieces together: the SNARE hypothesis}

By 1993, most of the major components of the neurotransmitter release machinery had been identified, but it was still not clear how they worked together to fuse vesicle and presynaptic membranes. In March of 1993, James Rothman's group demonstrated that syntaxin, VAMP/synaptobrevin, and SNAP25 bound to immobilized $\alpha$-SNAP and were released upon NSF-mediated ATP hydrolysis (56). Notably, this was the first article to dub these three proteins SNAREs. Based on these findings, Rothman proposed the SNARE hypothesis, which holds that transport vesicles find a target membrane when a SNARE protein on the vesicle (v-SNARE) pairs with its cognate SNARE on the target membrane ( $t$-SNARE). In November, Rothman and Scheller used a cell-free system to show that the SNARE proteins form a stable complex that binds synaptotagmin (57). They also showed that synaptotagmin was displaced by $\alpha$-SNAP, indicating that the two proteins share a binding site. Rothman and Scheller suggested that synaptotagmin functions to clamp the complexed SNARE proteins and prevent membrane fusion in the absence of an appropriate signal. One of the most important findings of this paper was that ATP hydrolysis by NSF dissociated the SNARE complex. These studies established the formation of the SNARE complex, but further studies were required to establish the timing and regulatory mechanisms required for vesicle fusion and neurotransmitter release. Throughout the 1990s and 2000s, Scheller and Südhof continued to explore the interactions among SNARE proteins and their regulators, continuously refining their theories on the molecular mechanisms underlying membrane fusion.

Scheller's studies were focused on the nature and specificity of SNARE interactions and the formation of the SNARE complex. Using fluorescence resonance energy transfer, Scheller studied the structural organization of the synaptic exocytosis complex, looking specifically at the interaction between the t-SNARE syntaxin and the v-SNARE VAMP. The finding of a parallel organization of the two proteins lead to the idea that formation of the SNARE complex drives membrane fusion, which drives vesicle fusion (58). These findings complemented electron microscopy studies by Heuser and Jahn, showing that the SNARE complex is composed of four parallel helices bundled together (59). Further, it was suggested that the role of $\alpha$-SNAP and NSF was to dissociate the SNARE complex after the fusion event so the proteins could recycle and be used for another round of membrane fusion (56). Scheller bolstered the role of SNARE proteins in synaptic vesicle exocytosis by investigating their function in a cell-based system. Using PC12 cells that had been "cracked" open by passage through a ball homogenizer, Scheller demonstrated that neurotransmitter release could be rescued after botulinum neurotoxin exposure by the addition of specific portions of SNAP25 and calcium (60). Through mutation of the SNARE complex, Scheller demonstrated that the energy of complex formation is directly linked to the rate of 
exocytosis. The cracked PC12 system also demonstrated that only specific combinations of SNAREs could form fusion-competent complexes, reaffirming the idea that SNAREs contribute to target membrane/ vesicle interaction specificity (61)

Südhof continued to focus on the nature of SNARE interactions and the role of calcium in membrane fusion. An examination of the interactions among the SNARE proteins revealed that binary combinations of any two of the three proteins (VAMP, SNAP25, and syntaxin) were relatively weak; however, a complex consisting of all three SNAREs via their helical SNARE domains greatly increased the strength of the complex so that it was resistant to SDS and neurotoxin-mediated cleavage (62). He determined that $\alpha$-SNAP binds to the fully formed VAMP/syntaxin/SNAP25 complex, suggesting that it was involved in later stages of the membrane fusion reaction (63). In a series of experiments using a variety of molecular biology and biochemical techniques, Südhof explored the role of synaptotagmin in exocytosis. He demonstrated that calcium binding alters the electrostatic potential of the protein, changing its conformation and interaction with syntaxin to drive membrane fusion (64-66). In addition to his studies of synaptotagmin, he identified other important regulators of vesicle exocytosis, including complexin, which binds to SNARE complexes in an assembled, but fusion-incompetent, state until an action potential arrives $(67,68)$. In binding to SNARE complexes, complexin not only clamps the complexes, but also activates them and serves as an essential cofactor for synaptotagmin, enabling fast, calcium-triggered neurotransmitter release (69).

The studies described above outlined an elegant ballet of molecular interactions that drive the fusion of neurotransmitter-filled vesicles with the plasma membranes of presynaptic nerve terminals. The SNARE proteins syntaxin, VAMP/ synaptobrevin, and SNAP25 form membrane-bridging complexes known as trans-SNARE complexes through the interaction of their helical SNARE domains (70). Each trans-SNARE complex is composed of four SNARE domains: one from VAMP/synaptobrevin on the vesicle and three from SNAP25 (which contains two SNARE domains) and syntaxin on the plasma membrane. In addition to the SNARE proteins, MUNC18/ nSEC1 (SM) proteins interact with syntaxin to promote trans-SNARE complex formation (47). Complexin binds to the trans-SNARE complex, preventing further SNARE interaction and spontaneous membrane fusion. At the same time, complexin activates the SNARE complex for synaptotagmin. An action potentialstimulated cellular calcium influx triggers the completion of SNARE assembly when calcium binds to vesicle-associated synaptotagmin, which displaces complexin and allows the SNAREs to zipper together, forming a cis-SNARE complex. The energy released during the formation of the cis-SNARE complex is enough to overcome the repulsive forces between the two membranes and catalyze membrane fusion. Once the membranes merge, a fusion pore opens, allowing neurotransmitter to spill into the synaptic cleft and stimulate receptors on the postsynaptic density of the receiving neuron (Figure 3 ).

\section{Legacy and future work}

Scheller and Südhof's elucidation of the molecular underpinnings of neurotransmitter release have contributed not only to our understanding of basic neuroscience, but also to human physiology and disease. Communication between neurons gives rise to our very consciousness; consequently, perturbations in neural communication lead to illnesses such as schizophrenia, depression, gait disturbances, and neurodegeneration (71-75). Moreover, SNARE-mediated exocytosis underlies regulated secretion in most homolog cell types. "What we discovered was the fundamental mechanism of membrane fusion that is used by all organisms. In a way, the brain was the best place to study this, because the proteins are so abundant. The brain makes use of membrane fusion as its main form of intercellular communication. We not only understood how synaptic vesicles are released, but the proteins that we characterized turned out to be the founding members of gene families that are expressed in all cells, yeast, plants, all the cells of our body, which mediate membrane trafficking from the ER to the Golgi, in endocytosis, and so on," said Scheller.

Südhof, now the Avram Goldstein Professor of Molecular and Cellular Physiology at Stanford University School of Medicine and a Howard Hughes Medical Institute Investigator, believes that there is more work to be done to have a clear understanding of the molecular mechanisms that influence human disease states. "We have to understand the patho- physiology of disease if we want to have a chance to influence it," said Südhof. "The brain is too complex [for us to be] able to understand it if we don't understand it at the molecular level. If we really want to understand it we have to get down to the molecules." Additionally, he thinks that improvements in human genomics will make a significant contribution to our understanding of disease. "I am convinced that the genomics revolution that happened over the last 10 years will have enormous lasting influence not only on basic biology, but also on neuroscience. I think we will have to change how we think based on developments that come out of that and are continuing to be developed." His current research is focused on how synapses are formed and how each synapse establishes a unique identity with specific qualities that influence the operation of neural circuits.

Scheller, now the Executive Vice President for Research and Early Development at Genentech, believes that additional genetic and biochemical information will contribute to our understanding of human disease and the ability to develop new treatments. "There has been a revolution in biology that's taken place in the last 25 years that has resulted in a huge amount of information that researchers were then able to use to understand the molecular basis of disease. Once you understand that molecular basis of a particular condition, you can rationally approach that condition and try and invent medicines," he said. Reflecting back on the research that characterized neurotransmitter release, Scheller said, "It was piecemeal. As you look at this beautiful, but complicated, system, you have to remember that you don't understand something like that all at once. There were a lot of little eureka moments that gave rise to the big picture."

By carefully and systematically identifying and characterizing the molecular mechanisms that mediate neurotransmitter release over a period of decades, Scheller and Südhof transformed our understanding of regulated exocytosis and a critical component of cellular communication. Additionally, they have provided some of the first clues to the underpinnings of brain function at the molecular level, opening up entirely new areas of research that will help us to understand some of the most essential functions in the human body.

\section{Jillian H. Hurst}


1. Bennett MR. The early history of the synapse: from Plato to Sherrington. Brain Res Bull. 1999; 50(2):95-118.

2. Ramon Y Cajal S. Structure and connections of neurons. Bull Los Angel Neuro Soc. 1952;17(1-2):5-46.

3. Winkelmann A. Wilhelm von Waldeyer-Hartz (1836-1921): an anatomist who left his mark. Clin Anat. 2007;20(3):231-234.

4. Del Castillo J, Katz B. Quantal components of the end-plate potential. J Physiol. 1954;124(3):560-573.

5. De Robertis ED, Bennett HS. A submicroscopic vesicular component of Schwann cells and nerve satellite cells. Exp Cell Res. 1954;6(2):543-545.

6. Palay SL. Synapses in the central nervous system. J Biophys Biochem Cytol. 1956;2(4 suppl):193-202.

7. Heuser J, Lennon AM. Morphological evidence for exocytosis of acetylcholine during formation of synaptosomes from Torpedo electric organ. J Physiol. 1973;233(1):39P-41P.

8. Heuser JE, Reese TS. Evidence for recycling of synaptic vesicle membrane during transmitter release at the frog neuromuscular junction. J Cell Biol. 1973; 57(2):315-344.

9. Llinas R, Nicholson C. Calcium role in depolarization-secretion coupling: an aequorin study in squid giant synapse. Proc Natl Acad Sci U S A. 1975; 72(1):187-190.

10. Katz B, Miledi R. Ionic requirements of synaptic transmitter release. Nature. 1967;215(5101):651.

11. Katz B, Miledi R. A study of synaptic transmission in the absence of nerve impulses. J Physiol. 1967; 192(2):407-436.

12. Katz B, Miledi R. The timing of calcium action during neuromuscular transmission. J Physiol. 1967; 189(3):535-544.

13. Sudhof TC, Lottspeich F, Greengard P, Mehl E, Jahn R. A synaptic vesicle protein with a novel cytoplasmic domain and four transmembrane regions. Science. 1987;238(4830):1142-1144.

14. Hooper JE, Carlson SS, Kelly RB. Antibodies to synaptic vesicles purified from Narcine electric organ bind a subclass of mammalian nerve terminals. J Cell Biol. 1980;87(1):104-113.

15. Trimble WS, Cowan DM, Scheller RH. VAMP-1: a synaptic vesicle-associated integral membrane protein. Proc Natl Acad Sci U S A. 1988;85(12):4538-4542.

16. Sudhof TC, Baumert M, Perin MS, Jahn R. A synaptic vesicle membrane protein is conserved from mammals to Drosophila. Neuron. 1989;2(5):1475-1481.

17. Elferink LA, Trimble WS, Scheller RH. Two vesicleassociated membrane protein genes are differentially expressed in the rat central nervous system. J Biol Chem. 1989;264(19):11061-11064.

18. Trimble WS, Gray TS, Elferink LA, Wilson MC, Scheller RH. Distinct patterns of expression of two VAMP genes within the rat brain. J Neurosci. 1990; 10(4):1380-1387.

19. Block MR, Glick BS, Wilcox CA, Wieland FT, Rothman JE. Purification of an $\mathrm{N}$-ethylmaleimide-sensitive protein catalyzing vesicular transport. Proc Natl Acad Sci U S A. 1988;85(21):7852-7856

20. Malhotra V, Orci L, Glick BS, Block MR, Rothman JE. Role of an N-ethylmaleimide-sensitive transport component in promoting fusion of transport vesicles with cisternae of the Golgi stack. Cell. 1988 54(2):221-227.

21. Weidman PJ, Melancon P, Block MR, Rothman JE. Binding of an $\mathrm{N}$-ethylmaleimide-sensitive fusion protein to Golgi membranes requires both a soluble protein(s) and an integral membrane receptor. J Cell Biol. 1989;108(5):1589-1596.

22. Beckers CJ, Block MR, Glick BS, Rothman JE, Balch WE. Vesicular transport between the endoplasmic reticulum and the Golgi stack requires the NEM-sensitive fusion protein. Nature. 1989; 339(6223):397-398.

23. Clary DO, Rothman JE. Purification of three related peripheral membrane proteins needed for vesicular transport. J Biol Chem. 1990;265(17):10109-10117.

24. Clary DO, Griff IC, Rothman JE. SNAPs, a family of NSF attachment proteins involved in intracellular membrane fusion in animals and yeast. Cell. 1990; 61(4):709-721.

25. Wilson DW, Whiteheart SW, Wiedmann M, Brunner M, Rothman JE. A multisubunit particle implicated in membrane fusion. J Cell Biol. 1992; 117(3):531-538.

26. Whiteheart SW, Brunner M, Wilson DW, Wiedmann M, Rothman JE. Soluble N-ethylmaleimidesensitive fusion attachment proteins (SNAPs) bind to a multi-SNAP receptor complex in Golgi membranes. J Biol Chem. 1992;267(17):12239-12243.

27. Katz B, Miledi R. Further study of the role of calcium in synaptic transmission. J Physiol. 1970; 207(3):789-801.

28. Matthew WD, Tsavaler L, Reichardt LF. Identification of a synaptic vesicle-specific membrane protein with a wide distribution in neuronal and neurosecretory tissue. J Cell Biol. 1981;91(1):257-269.

29. Perin MS, Fried VA, Mignery GA, Jahn R, Sudhof TC. Phospholipid binding by a synaptic vesicle protein homologous to the regulatory region of protein kinase C. Nature. 1990;345(6272):260-263.

30. Perin MS, Johnston PA, Ozcelik T, Jahn R, Francke U, Sudhof TC. Structural and functional conservation of synaptotagmin (p65) in Drosophila humans. J Biol Chem. 1991;266(1):615-622.

31. Geppert M, Archer BT, Sudhof TC. Synaptotagmin II. A novel differentially distributed form of synaptotagmin. J Biol Chem. 1991;266(21):13548-13552.

32. Wendland B, Miller KG, Schilling J, Scheller RH. Differential expression of the p65 gene family. Neuron. 1991;6(6):993-1007.

33. Li C, Ullrich B, Zhang JZ, Anderson RG, Brose N, Sudhof TC. Ca(2+)-dependent and -independent activities of neural non-neural synaptotagmins. Nature. 1995;375(6532):594-599.

34. Perin MS, Brose N, Jahn R, Südhof TC. Domain structure of synaptotagmin (p65). J Biol Chem. 1991; 266(1):623-629.

35. Davletov BA, Sudhof TC. A single C2 domain from synaptotagmin I is sufficient for high affinity Ca2+/phospholipid binding. J Biol Chem. 1993; 268(35):26386-26390.

36 . Leveque $\mathrm{C}$, et al. The synaptic vesicle protein synaptotagmin associates with calcium channels and is a putative Lambert-Eaton myasthenic syndrome antigen. Proc Natl Acad Sci U S A. 1992;89(8):3625-3629.

37. Petrenko AG, Perin MS, Davletov BA, Ushkaryov YA, Geppert M, Sudhof TC. Binding of synaptotagmin to the alpha-latrotoxin receptor implicates both in synaptic vesicle exocytosis. Nature. 1991; 353(6339):65-68.

38. Bennett MK, Calakos N, Scheller RH. Syntaxin: a synaptic protein implicated in docking of synaptic vesicles at presynaptic active zones. Science. 1992;257(5067):255-259.

39. Inoue A, Obata K, Akagawa K. Cloning and sequence analysis of cDNA for a neuronal cell membrane antigen, HPC-1. J Biol Chem. 1992; 267(15):10613-10619.

40. Geppert M, et al. Synaptotagmin I: a major $\mathrm{Ca} 2+$ sensor for transmitter release at a central synapse. Cell. 1994;79(4):717-727.

41. Fernandez-Chacon R, et al. Synaptotagmin I functions as a calcium regulator of release probability. Nature. 2001;410(6824):41-49.

42. Pang ZP, et al. Synaptotagmin-2 is essential for survival contributes to $\mathrm{Ca} 2+$ triggering of neurotransmitter release in central neuromuscular synapses. $J$ Neurosci. 2006;26(52):13493-13504.

43. Hirning LD, et al. Dominant role of $\mathrm{N}$-type Ca2+ channels in evoked release of norepinephrine from sympathetic neurons. Science. 1988;239(4835):57-61.

44. Bennett MK, et al. The syntaxin family of vesicular transport receptors. Cell. 1993;74(5):863-873.
45. Oyler GA, et al. The identification of a novel synaptosomal-associated protein, SNAP-25, differentially expressed by neuronal subpopulations. J Cell Biol. 1989;109(6 pt 1):3039-3052.

46. Hata Y, Slaughter CA, Sudhof TC. Synaptic vesicle fusion complex contains unc-18 homologue bound to syntaxin. Nature. 1993;366(6453):347-351.

47. Pevsner J, Hsu SC, Scheller RH. n-Sec1: a neuralspecific syntaxin-binding protein. Proc Natl Acad Sci US A. 1994;91(4):1445-1449.

48. Sudhof TC, Rothman JE. Membrane fusion: grappling with SNARE and SM proteins. Science. 2009; 323(5913):474-477.

49. Schiavo G, et al. Tetanus and botulinum-B neurotoxins block neurotransmitter release by proteolytic cleavage of synaptobrevin. Nature. 1992; 359(6398):832-835.

50. Link E, et al. Tetanus toxin action: inhibition of neurotransmitter release linked to synaptobrevin proteolysis. Biochem Biophys Res Commun. 1992; 189(2):1017-1023.

51. McMahon HT, et al. Cellubrevin is a ubiquitous tetanus-toxin substrate homologous to a putative synaptic vesicle fusion protein. Nature. 1993; 364(6435):346-349.

52. Blasi J, et al. Botulinum neurotoxin A selectively cleaves the synaptic protein SNAP-25. Nature. 1993; 365(6442):160-163.

53. Schiavo G, et al. Botulinum neurotoxins serotypes $A$ and E cleave SNAP-25 at distinct COOH-terminal peptide bonds. FEBS Lett. 1993; 335(1):99-103

54. Blasi J, Chapman ER, Yamasaki S, Binz T, Niemann $\mathrm{H}$, Jahn R. Botulinum neurotoxin C1 blocks neurotransmitter release by means of cleaving HPC-1/ syntaxin. EMBO J. 1993;12(12):4821-4828.

55. Schiavo G, Shone CC, Bennett MK, Scheller $\mathrm{RH}$, Montecucco C. Botulinum neurotoxin type $\mathrm{C}$ cleaves a single Lys-Ala bond within the carboxyl-terminal region of syntaxins. J Biol Chem. 1995;270(18):10566-10570.

56. Sollner T, et al. SNAP receptors implicated in vesicle targeting and fusion. Nature. 1993; 362(6418):318-324.

57. Sollner T, Bennett MK, Whiteheart SW, Scheller $\mathrm{RH}$, Rothman JE. A protein assembly-disassembly pathway in vitro that may correspond to sequential steps of synaptic vesicle docking, activation, and fusion. Cell. 1993;75(3):409-418.

58. Lin RC, Scheller RH. Structural organization of the synaptic exocytosis core complex. Neuron. 1997; 19(5):1087-1094.

59. Hanson PI, Roth R, Morisaki H, Jahn R, Heuser JE. Structure and conformational changes in NSF and its membrane receptor complexes visualized by quick-freeze/deep-etch electron microscopy. Cell. 1997;90(3):523-535.

60. Chen YA, Scales SJ, Patel SM, Doung YC, Scheller RH. SNARE complex formation is triggered by $\mathrm{Ca} 2+$ and drives membrane fusion. Cell. 1999; 97(2):165-174

61. Scales SJ, Chen YA, Yoo BY, Patel SM, Doung YC, Scheller R H. SNAREs contribute to the specificity of membrane fusion. Neuron. 2000;26(2):457-464.

62. Hayashi T, et al. Synaptic vesicle membrane fusion complex: action of clostridial neurotoxins on assembly. EMBO J. 1994;13(21):5051-5061.

63. McMahon HT, Sudhof TC. Synaptic core complex of synaptobrevin, syntaxin, and SNAP25 forms high affinity alpha-SNAP binding site. J Biol Chem. 1995; 270(5):2213-2217.

64. Shao X, Li C, Fernandez I, Zhang X, Sudhof TC, Rizo J. Synaptotagmin-syntaxin interaction: the C2 domain as a $\mathrm{Ca} 2+-$ dependent electrostatic switch. Neuron. 1997;18(1):133-142.

65. Ubach J, Zhang X, Shao X, Sudhof TC, Rizo J. Ca2+ binding to synaptotagmin: how many Ca2+ ions bind to the tip of a C2-domain? EMBO J. 1998; 
17(14):3921-3930.

66. Davletov BA, Sudhof TC. $\mathrm{Ca}(2+)$-dependent conformational change in synaptotagmin I. J Biol Chem. 1994;269(46):28547-28550.

67. McMahon HT, Missler M, Li C, Sudhof TC. Complexins: cytosolic proteins that regulate SNAP receptor function. Cell. 1995;83(1):111-119.

68. Tang J, Maximov A, Shin OH, Dai H, Rizo J, Sudhof TC. A complexin/synaptotagmin 1 switch controls fast synaptic vesicle exocytosis. Cell. 2006; 126(6):1175-1187.
69. Maximov A, Tang J, Yang X, Pang ZP, Sudhof TC. Complexin controls the force transfer from SNARE complexes to membranes in fusion. Science. 2009; 323(5913):516-521

70. Weber T, et al. SNAREpins: minimal machinery for membrane fusion. Cell. 1998;92(6):759-772.

71. Johnson RD, Oliver PL, Davies KE. SNARE proteins and schizophrenia: linking synaptic and neurodevelopmental hypotheses. Acta Biochim Pol. 2008; 55(4):619-628.

72. Catterall WA, Few AP. Calcium channel regula- tion and presynaptic plasticity. Neuron. 2008; 59(6):882-901.

73. Brose N. Altered complexin expression in psychiatric and neurological disorders: cause or consequence? Mol Cells. 2008;25(1):7-19.

74. Gissen P, Maher ER. Cargos and genes: insights into vesicular transport from inherited human disease. J Med Genet. 2007;44(9):545-555.

75. Chua CE, Tang BL. $\alpha$-Synuclein and Parkinson's disease: the first roadblock. J Cell Mol Med. 2006; 10(4):837-846 